\title{
INTERMODAL AND INTRAMODAL COMPETITION IN PASSENGER RAIL TRANSPORT
}

\author{
Marc Ivaldi* and Catherine Vibes ${ }^{\circ}$
}

March 23, 2005

\begin{abstract}
The objective of the paper is to elaborate a simulation model to analyze interand intra-modal competition in the transport industry, based on game theory models. In our setting, consumers choose a transport mode and an operator to travel on a given city-pair; operators strategically decide on prices for the types of service they provide. We derive the market equilibrium and simulate potential scenarios. In particular we measure the impact of entry by a low cost train operator and the effect of a kerosene tax. Hence our framework could serve as a tool to measure the effectiveness of competition on a relevant market or to design marketing strategies. More generally it can be applied in cases of oligopolistic competition when detailed data are not available.
\end{abstract}

Acknowledgement: We are grateful to Moneim Eltohami, Guido Friebel, Markus Ksoll, Erhard Michel, Marko Niffka, Paul Seabright, Frank Wagner and Christiane Warnecke for valuable comments and insights on earlier versions. We also thank participants to the Second Conference on Railroad Industry Structure, Competition and Investment, (Evanston, October 7-8, 2004) and to Séminaire d'Economie Industrielle (Direction de la Prévision, Ministère de l'Economie, des Finances et de l'Industrie, Paris, September 30, 2004) for their useful comments. The authors acknowledge with gratitude the support of Die Bahn that provided data. However the views expressed remain those of the authors and in no way represent the official or unofficial views of Die Bahn or its representatives.

JEL Classification: L11, L13, L92, L93, L98, C81, C35

Keywords: Product differentiation, relevant transport market, simulation model.

\footnotetext{
${ }^{*}$ University of Toulouse (IDEI), EHESS and CEPR

University of Toulouse (MPSE, GREMAQ and IDEI).
} 


\section{Introduction}

This paper presents a simulation model to analyze inter- and intra-modal competition in the transport industry, based on game theory models. In our setting, consumers choose a mode and an operator to travel on a given city-pair, and firms decide on service quality and prices. From these assumptions we derive the market equilibrium and simulate potential scenarios. The model allows us to evaluate the effects of both structural and regulatory changes on a particular market. More precisely, we are able to measure the impacts of either entry by a new rail operator, or a change in the regulatory framework with the introduction of a kerosene tax for example. In this sense the model could serve as a tool to measure the effectiveness of competition on a relevant market or to design marketing strategies.

These issues arise within a context of successive liberalization processes in the world, and more particularly in Europe. The airline industry was the first passenger transport sector to be deregulated and open to competition. In Europe, the process started in 1987 to end up in 1992 with the "third package", the full implementation of liberalization laws becoming effective in 1997. Airlines are then free to set prices, there are no limits in capacity shares, and all airlines from the community have free access to the market. Moreover, the evolution of the general network configuration into a hub-and-spokes network, and the incentives for companies to reduce costs, increase connections and boost demand, has induced a recent effect on competition in this sector. As this network structure imposes barriers to the entry of new operators on the quasi-monopolistic routes originating from the hub, a new category of airlines entered on some niche markets, specifically, on point-to-point routes. These companies are characterized by very low costs allowing them to propose lower prices. Some Low Costs Airlines are highly profitable and are gaining more and more market share in the European market. These two main changes in the structure of the air transport industry, the deregulation and the entry of Low Cost Airlines, make intra-modal competition tougher and tougher in this sector.

The liberalization process of the European railways industry started in 1991. The European Commission, in its Directive 91/440, announces three main objectives to promote railways: to increase their market share, to reduce subsidies and to liberalize access to infrastructure to enhance competition. However, the provisions of Directive 91/440 do not go far enough as they only apply to international cooperations in cross border transport and do not include cabotage. Only a few countries have gone b eyond the EU regulation, introduced competition and experienced the entry of new competitors on their tracks, notably UK and 
Germany. The EU commission has initiated a new directive to fully open up international passenger rail transport. Once the market is open, competition should be expected to happen quite rapidly as existing railways companies face lower entry costs than totally new entrants. This new intra-modal competition in the railways sector is expected to develop in all European countries, including the most recent additions to the EU. It would change the whole nature of competition in this industry.

Before the 1990's, rail and air transport were considered as two modes not competing with each other, because of the large differences existing in the services provided, for example concerning travel time and tariffs. This is not true anymore. The development of High Speed technology reduced considerably the gap between air and train travel time from city-center to city-center, and the appearance of Low Cost Airlines makes plane tickets affordable by a high share of the population. So not only airlines and train operators are facing separately intramodel competition, but now these technical and structural changes introduce a real and fierce inter-modal competition between airlines and train operators. Antes, Friebel, Niffka and Rompf (2004) investigate these effects in a case study on the entry of Low Cost Airlines on the German passenger transportation market.

Finally these two industries have also to account for the most important competitor in terms of market shares, namely private car, with the advantage of providing full scope for the driver to travel at any time.

The preceding analysis leads us to the need of considering transport between an origin and a destination as one market with differentiated products competing with each other. Now, passengers can choose between several modes and even several companies or alternatives within modes to provide them the transport service they are looking for.

This product differentiation is due to the fact that passengers have different valuations for the service offered by an operator, and it is used strategically by competitors to avoid a fierce price competition. Proposing different services, the operators target different segments of the population, and this behavior affects pricing decisions. ${ }^{1}$ When such a market is being analyzed empirically, several questions arise. The first one deals with the determination of the number of products on the market, requiring a precise analysis of consumers' choices usually collected through questionnaires. Fortunately, in mode choice modeling, the number of alternatives is usually small. Secondly, from an econometric point of view, one should be aware of the important data collection needed in such disaggregated models. Precise

\footnotetext{
${ }^{1}$ IDEI (2003) discusses the role of product differentiation in the competition process in details.
} 
information is required concerning the socioeconomic status of the traveler (income, household composition, etc), the nature of the trip (motivation), and the characteristics of alternative modes (travel time, frequency, etc). These data are usually gathered through time demanding and costly questionnaire surveys, each of them being specific to the city-pair under consideration, as well as the category of consumers. We present later a methodology avoiding the difficult task of collecting rare and detailed data for a specific application.

In this particular differentiated-product market, we model demand and supply in order to recover equilibrium outcomes. Market demand is derived from a general class of discrete choice models of consumer behavior. Travelers can first choose the mode they want to travel with, then within this mode, decide on a specific service. For this discrete choice structure, an appropriate specification for an empirical analysis is the nested logit model. On the supply side, firms determine prices and quality of the service they provide. Market outcomes are derived within the context of a Nash equilibrium. Firms behave strategically: Each of them determines its prices knowing that its competitors do the same. An increase in one firm's price has a positive impact on its margin but a negative one on its traffic. This can lead to a traffic increase for the other competitors who may want in turn to set slightly higher prices to increase their margins. The equilibrium outcomes are then dependent on own- and cross-price demand elasticities.

This essential aspect of competition is usually left aside in models analyzing only the demand side of the market. Preston, Wardman and Whelan (1999) analyze the impact of entry on an inter-city rail line. They estimate a demand model, a cost model, and simulate different forms of competition. However they do not have a partial equilibrium model. They find that competition is possible in a situation with costs reductions and/or product differentiation. More recently, Johnson and Whelan (2003) present a demand-cost model developed by the Institute of Transport Studies (University of Leeds), to look at the potential for on-track competition in the UK. They use it to measure the impact of alternative ticket sales on one city-pair and find some significant differences in terms of revenue. Another study conducted by Glass (2003) applies the same demand-cost model as the one used by Johnson and Whelan to another particular link, incorporating a game theoretical model, and his main conclusion is that head-on competition in the market is socially desirable because the increase in consumer surplus more than compensates firms' losses. However note that all these studies concentrate only on intra-modal competition and do not consider inter-modal competition, and they do not account for competitors' reactions to a change in the market, leading to a new equilibrium. 
As an example, we apply our model of intra- and inter- modal competition to a particular city-pair in Germany, specifically the link Cologne-Berlin. This link is of particular interest here because all forms of competition described earlier are represented: a national air carrier Lufthansa (LH), three Low Costs Airlines, the rail incumbent operator Deutsche Bahn AG (DB), the threat of entry from other railways, and road.

This paper is organized as follows. Section 2 details the city-pair and associated data chosen to apply our methodology. Section 3 presents the demand-and-supply model on this market and discusses the equilibrium features. Then the calibration method is explained in section 4. Finally, section 5 provides the results of counterfactual experiments, which allows us to evaluate the implications of potential evolutions on the market configuration, such as the plausible entry of a low cost rail competitor, or the regulatory changes affecting costs of the companies present on the market. Section 6 draws some preliminary concluding remarks.

\section{Data on a generic example}

We motivate our modeling framework by considering a specific example: the passenger traffic modal competition on the link Cologne-Berlin in Germany. This O-D pair is appropriate for three main reasons. First, this link, which is a $600 \mathrm{~km}$ long route connecting two of the largest German cities from west to east of the country, represents a significant share of total long distance passenger traffic in Germany. Second, because of these geographical features, it involves a diversity of travelers (business, leisure...) which probably explains the differentiation in transport services provided between Cologne and Berlin. Not only there exist several transport modes, but there are also several active airlines. Three main passenger travel modes are available on this link: rail (DB), road and air. The air service is provided by three recently entered Low Cost Airlines (LCA), namely DBA, Germanwings (GW) and Hapag-Lloyd Express (HLA) on the market, in addition to Lufthansa (LH). The LCAs' growing popularity is fueled by their offer of competitive prices, which, according to these airlines, are mainly driven by a low cost structure. This alternative is attractive as the air service is no longer an expensive solution while it is often considered as a faster transport mode than rail. Moreover, not only these LCAs are direct competitors to Lufthansa and DB, but, by challenging Lufthansa, they force this airline to enter in a fiercer competition with DB. Last not least the relation already experienced intramodal competition in passenger rail 
transport. During 2003, Connex operated a daily service on the link. It was not very frequented and given up when Connex needed the rolling stock on another link with a public service contract.

All these elements motivate our interest for analyzing the functioning of inter- and intramodal competition in this context and for simulating the effects of possible exit or entry on this market recently opened to competition on the rail segment, as well as the changes of public policy aiming for example at encouraging rail travel or reducing exhaust emissions.

Most of the data on traffic, alternative characteristics and prices has been provided by Deutsche Bahn AG. For every transport mode and the two main categories of passengers (business and leisure), the price measured in Euros corresponds to the most common price that a representative customer usually pays for a trip between Cologne and Berlin. Concerning services characteristics, we have available speed measured in kilometers per minute $(\mathrm{km} / \mathrm{min})$, frequency per day, and capacity per day (seats available per trip). Some values for marginal costs are also provided by DB. Descriptive statistics are provided in Table 1.

\section{The economic model}

In this section we present a framework for describing intra- and inter- modal competition between transport alternatives, with the example of the Cologne-Berlin link as a background. In the next section this model is calibrated using the data collected on this specific link and then it can be applied to evaluate the effects of exit or entry of a new competitor and the changes in product characteristics or in prices.

In such a differentiated-products framework and oligopoly structure, firms are competing both in terms of prices and product characteristics. Here we focus on price competition assuming that, in the short run, product characteristics are fixed. First we describe the demand side, then we derive the pricing strategy of firms involved in a Bertrand-Nash competition.

\section{Demand side}

We consider the choices made by potential travelers willing to travel from Cologne to Berlin, in terms of mode and service provided. Three transport modes (rail, air, road) are present on the link, with a diversification on the air segment: three LCAs and the incumbent carrier, Lufthansa. The alternatives are characterized by a quality parameter and a price. 
In addition we assume the existence of an outside alternative: Instead of choosing one of the services offered to travel from Cologne to Berlin, consumers may decide not to make the trip. Hence the total market size is defined as the number of consumers who would be potentially interested in making the trip.

The potential travelers for a one way trip from Cologne to Berlin are heterogeneous. We consider two main categories in the passengers' population: business and leisure travelers. They differ for example by their requirements in terms of schedules and prices. In what follows, we account for these two types of passengers by considering two separate markets: the business market and the leisure market. There are $N_{B}$ (respectively, $N_{L}$ ) potential travelers on the business (leisure) market who may either travel using one of the transport services supplied, or otherwise choose not to travel (the outside alternative). In the sequel, the two markets are treated symmetrically and we skip indexes $B$ and $L$ without loss of generality.

Assume that each consumer makes its choice in a sequential way: she decides about the transport mode and then the service to travel with. The consumer choice structure is depicted in Appendix 1. A choice, i.e., an alternative or a product is then a combination of a transport mode and a service provided by a transport operator. Note that for road, the transport operator is the driver in her car. There are $J$ alternatives classified into $G$ groups. Here we have four groups $g=0,1, \ldots, G$ where group 0 corresponds to the outside alternative (herein, OG), the other groups correspond to the ones of three modes, i.e., rail, air, road.

Consumers' utility depends on quality and prices. We attribute a quality index $\psi_{j}$, and a price $p_{j}$, to every alternative. The utility function associated with alternative $j(j=1,2, \ldots, J)$ is written as follows:

$$
U_{i j}=V_{j}+\varepsilon_{i j}
$$

where $V_{i}$ represents the mean utility level common to every passenger (the deterministic part) and $\varepsilon_{i j}$ (the random part) corresponds to the departure of consumer $i$ from the common utility level, specific to product $j$, i.e., to the unknown consumer $i$ 's tastes on product $j$. This mean utility level can be further decomposed as:

$$
V_{j}=\psi_{j}-h p_{j}
$$

where $h$ represents the sensitivity of utility to price, or marginal utility of income. 
We adopt here a nested logit specification for the random preferences. In this framework, products within the same group are closer substitutes than products from different groups. To allow for this dependence and correlation between the utilities of alternatives in common groups, the random part can be specified as the weighted sum of unobserved variables, which represent consumer $i$ 's taste for any alternative belonging to group $\mathrm{g}$ :

$$
\varepsilon_{i j}=\sigma v_{i g}+(1-\sigma) v_{i j}, \quad \forall i=1, \ldots, N
$$

The parameter $\sigma$ is to be estimated and gives a measure of degree of correlation between alternatives belonging to the same group: The higher $\sigma$, the higher the correlation between alternatives of the same group. The parameter $\sigma$ must lie between 0 and 1. For this reason, $\sigma$ is the degree of intragroup correlation. The random components $v_{i g}$ and $v_{i j}$ are assumed to be distributed such that each term, and consequently $\varepsilon_{i j}$, has the standard extreme value distribution.

The consumer chooses the utility-maximizing alternative $j$ belonging to group $\mathrm{g}$ that satisfies:

$$
U_{i j} \geq U_{i j^{\prime}}, \quad \forall j^{\prime} \neq j
$$

Given the preceding specification of the random indirect utility function, the distribution assumptions on the error terms, the consumer's choice, and assuming that the mean utility of the outside good is set to 0 , we can compute the probability of choosing alternative $j$ from the probability of choosing group $g$ and the probability of choosing alternative $j$ conditional on choosing group $g$. Applying the methodology proposed by Berry (1994) which consists in expressing the mean utility level as a function of observed market shares that are replaced measures of choice probabilities, we derive the specification of demands associated with each alternative:

$$
\ln \left(s_{j}\right)-\ln \left(s_{0}\right)=\psi_{j}-h p_{j}+\sigma \ln \left(s_{j / g}\right)
$$


where the market shares $s_{j}$ and $s_{j / g}$ are defined as $s_{j}=\frac{q_{j}}{N}$, and $s_{j / g}=\frac{q_{j}}{N_{g}}, j=0,1, \ldots, J$, respectively, where in turn, $q_{j}$ is the quantity of product $j$ on the market (either business or leisure), $N$ is the size of that market and $N_{g}$ the size of market segment g. With this specification, we obtain the own price elasticities of demand as

$$
\eta_{j}=\frac{d q_{j}}{d p_{j}} \times \frac{p_{j}}{q_{j}}=h p_{j}\left[s_{j}-\frac{1}{1-\sigma}+\frac{\sigma}{1-\sigma} s_{j / g}\right] \quad \forall j \in g
$$

\section{Supply side}

In our framework, each firm provides one product, i.e., one transport service for the citypair. First, we consider the mode-service 'road and car' as offered by a firm competing with the other alternatives. Second, for all other transport services supplied on the city-pair under consideration, firms choose transport prices in order to maximize profits, knowing that their competitors do the same ${ }^{2}$.

$$
\pi_{j}=\left(p_{j}-c_{j}\right) q_{j}-K
$$

where $K$ represents fixed costs. They enter in a Bertrand-Nash competition. As in Ivaldi and Verboven (2004), the outcome of this Nash equilibrium is defined by a set of $J$ necessary first order conditions:

$$
p_{j}=c_{j}+\frac{1-\sigma}{h\left(1-\sigma s_{j / g}-(1-\sigma) s_{j}\right)}
$$

where $s_{j / g}$ is the market share of alternative $j$ in group $g$ and $s_{j}$ is the market share of alternative $f$ in the total market. The price of product $j$ is equal to the marginal cost of product $j$ plus a markup term.

The solution to the equilibrium is obtained by solving the system of Equations (5) and (8).

\section{Calibration}

\footnotetext{
${ }^{2}$ One may question the assumption that the service "road and car" is provided by a profit maximizing firm. Alternatively we could have assumed that the firm sets the price just to cover average cost. When we estimate a model in which prices for car are set equal to average costs, we do not find a significant difference with the case of profit maximizing firms.
} 
As a set of consistent data collected on a regular basis is not available here, we cannot proceed to the statistical estimation of the previous equilibrium model. We propose instead to calibrate it using some data on prices, markets shares, characteristics of transport services, and some values for marginal costs. All the computations for the calibration and later, the simulations, are achieved using the GAUSS software.

The system is solved numerically which allows us to compute demand parameters, as well as demand elasticities, consumer surplus and marginal costs. Given the available data and the structure of the model, several steps are needed for the calibration.

First, the demand parameters $h$ and $\sigma$ are computed by inverting the expressions for elasticities as defined in Equation (6). Then, firms' marginal costs are recovered using the markup defined by Equation (8) and the calibrated values for $h$ and $\sigma$. However, some care has to be taken to achieve this step of computations, as we do not have data on elasticities and we only know some values for marginal costs for the leisure market. We generate repeatedly a random vector of elasticities making some reasonable assumptions on their distribution using estimates of transport elasticities available in the literature (Oum, Waters and Young, 1990). For each draw, we are able to associate a value for parameters $h$ and $\sigma$ and to compute marginal costs. This procedure is repeated until we find a vector for marginal cost as close as possible from the values of marginal costs that we already know. We keep the latest values for $h, \sigma$, and the values of elasticities and marginal costs. For the business market, this procedure cannot be applied as marginal costs are unknown for that market so that the model can not be calibrated as precisely as for the leisure market.

Second, at this point we are able to calculate the values for the quality parameters, $\psi_{j}$, by inverting the equations defining market shares in Equation (5). Now we are interested in finding the weight associated to each component that enters in the quality index. We consider three standard dimensions of transport service quality: speed, frequency and capacity. Given the known values for these components of all transport services, we solve numerically a system of linear equations to recover the weights which allows us to derive consumers' valuations for the different components of quality.

A detailed description of computations is provided in Appendix 3. Applying this procedure yields the results gathered in Table 2 .

As mentioned earlier, we consider two separate markets: one for business travelers and one for leisure travelers. We also assume that the share of the outside alternative, i.e., 
customers who do not travel, represents $15 \%, 30 \%$ or $60 \%$ of the total population of potential travelers, i.e., the market size. The first half of Table 2 presents the values of market shares of the different alternatives, measured according to our market size based on potential travelers. Then Table 2 provides the values of two parameters of consumers' utility function: marginal utility of income and coefficient of intragroup correlation. The first one is interpreted as the sensitivity of utility to price. We can read that it is higher for leisure passengers $(h \approx 0.030)$ than for business passengers $(h \approx 0.016)$, as we could expect. The second parameter is a measure of correlation of alternatives belonging to the same mode. This parameter being closer to zero than to one $(0.20<\sigma<0.40)$ in both markets, we conclude that customers do not value more the mode than the alternative itself. (See the definition of $\sigma$ in Section 2.) This may be due to the fact that there is not much variability between Low Costs Airlines attributes, or that LCAs can be interpreted as substitutes for land transports as well.

Table 2 also provides estimates for own price elasticities of demand. First, note that these values are specific to the Cologne-Berlin city-pair and as such, they may not be comparable to national level measures. Indeed, here the traffic distribution between modes and types is different from what we observe from time series tables for European countries (European Commission: Energy and Transport in figures, 2003). In addition, on this link the degree of competition is higher, leading to higher elasticities (within Germany, other OD pairs are operated by less than 3 airlines). Second, we can see that the ranking of these elasticities with respect to services differs with passengers types. For business travelers the elasticity is higher for airlines services, whereas it is higher for car in the leisure segment. This result helps us deciding what should be the most probable value for the market share associated with the outside alternative. If we refer to the values of elasticities provided by Oum, Waters and Young (1990), a reasonable configuration would be to consider that non-travelers represent $15 \%$ of the business market and $30 \%$ of the leisure market.

Finally, Table 2 provides the values for consumer surplus showing that the consumer surplus derived from traveling decreases as the number of non-travelers increases.

Table 3 summarizes the measures of quality of service. The upper part of Table 3 displays the values for the quality effect of each provider of transport service on the consumers' utility. Note again a discrepancy between the two categories of travelers. Business passengers value more a service provided by Lufthansa or another airline than any other mode. On the contrary, leisure passengers are more attracted to train or car services than to airlines. This is quite intuitive, as schedules and travel time matter a lot for someone on a business trip, compared to someone on a leisure trip. 
The second half of Table 3 provides the valuations of the different components of quality. Recall that the quality index is expressed as the weighted sum of components affecting quality (idiosyncratic effect of the transport service provider, speed, frequency, capacity). The parameters associated with the alternative-specific dummy variables have to be interpreted as a fixed effect on quality once the effects of speed, frequency and capacity are taken into account, relatively to the quality of the omitted mode, car. It is not surprising to find a high negative coefficient for the Lufthansa dummy, as all attractive aspects of quality for this operator have already been accounted for (speed, frequency and capacity), and, what remains, is flexibility, possibility to stop during the trip for example, for which car performs better. The weights are then transformed into a monetary valuation of these different components of quality for each of the two categories of travelers. Consider the case where the outside alternative has a market share of $15 \%$ on the business market and $30 \%$ on the leisure market. The values for the quality characteristics are interpreted as follows. For business travelers, an increase in speed by 1 kilometer per minute, or 60 kilometers per hour, is equivalent to a reduction in price by 58.75 Euros, while for leisure travelers it is equivalent to a price reduction of 30.3 Euros. Business passengers have a higher valuation for speed than leisure passengers do. If we look at a unit positive variation in the alternatives respective frequencies, we find on the business market that it has the same effect as reducing price by 0.4 Euros for DB, 1.4 Euros for DBA, 3.3 Euros for HLX, 5 Euros for GW and 1.1 Euros for LH. These effects are similar on the leisure market. Moreover, increasing the frequency of DB service by 2 for business travelers is equivalent to increase speed by $0.7 \mathrm{~km} / \mathrm{h}$, and this corresponds to a price reduction of 0.67 Euro. Business travelers are almost indifferent in a frequency improvement of train service. However, adding 2 more flights per day to the GW schedules results in the same increase in utility as a $8.3 \mathrm{~km} / \mathrm{h}$ faster trip or a reduction of 8.2 Euros in the plane ticket. This is due to the fact that business travelers favor air transport more than land transport and that DB has already a high number of daily trips compared to GW. There is a decreasing marginal utility to frequency. Overall these results comfort our intuition. We can now move on and use the model for simulating counterfactual experiments.

\section{Simulations}


Once the equilibrium parameters are known, simulations for new market configuration can be run. The impact of any change in prices, quality characteristics, marginal costs, or even the entry or exit of a competitor can be measured, in terms of variations in the other firms' prices and market shares.

\section{The entry of InterConnex on the Cologne-Berlin link}

The train operator Connex decided to operate on the market in 2002 and exited in 2003. Simulate this entry allows us to measure the effects on all the competitors, to account for their price reactions, and so to evaluate the commercial feasibility of this entry. We find that the market shares of Connex are expected to be very low, this being mainly due to a low service quality level offered to travelers, particularly with respect to travel time, and to price levels not being as attractive as LCAs. In some sense, our model explains the effective exit of Connex. ${ }^{3}$

\section{Entry of Low Cost Airlines in 2001}

In order to validate the prediction power of our model, we apply it to the same market in 2001, before the entry of LCAs. At that time, only DB, DBA and Lufthansa were operating the market, and the cost structure of DBA was closer to the one of a regular company. We look here at the impact of the entry of two LCAs, namely HLX and GW, on the market in 2002 , taking into account the changes in costs for DBA being considered now as an additional LCA. Having information on these entrants' characteristics and marginal costs, we are able to measure the reaction in terms of prices for the different competitors and derive the corresponding market shares. Some remarks have to be made on the methodology. First, for identification reasons, we normalize the components of quality: speed, frequency and capacity, by setting their mean to 0 and standard deviation to 1 . Second, we focus on the leisure market, first because LCAs are targeting this market and second because we do not have information on marginal costs for the business category, which makes the calibration less precise. This lack of information becomes crucial, when instead of just looking at changes in equilibrium values, we need predictions of exact magnitudes. Finally, when presenting the results, we assume that the share of potential travelers in 2001 can take the values $20 \%, 35 \%$ and $65 \%$ to account for traffic induced by LCAs leading to a smaller share

\footnotetext{
${ }^{3}$ It should be noted, however, that the Interconnex service was not primarily directed at Cologne-Berlin travelers. But apparently, the market share on intermediate ODs was not on a sustainable level either.
} 
of the outside alternative in 2003. This allows us to compare the predicted market shares with the one we observe in 2003. The results are presented in Table 4.

By comparing the predicted market shares to observed market shares provided in Table 2, we can see that they are very close. For example, with a $30 \%$ share of the alternative, the observed market shares for airlines go from $3.5 \%$ to $6.4 \%$, the predicted ones from $3.9 \%$ to $6.5 \%$, and the ranking between alternatives is the same. Predicted prices are also very similar to what we observe, between 46 Euros and 52 Euros for LCAs.

\section{On-rail competition: The entry of a Low Cost Train}

Our third simulation consists in a structural change in the market, directly related to the liberalization process in the railways industry. We evaluate the consequences of the entry of a new operator on the link, providing exactly the same service as DB's, but benefiting from a more efficient cost structure: this new entrant is assumed to face half DB's marginal costs. We call this competitor Low Cost Train, and the results are presented in Table 5.

What happens in this context of tougher competition? First, prices decrease for all alternatives, particularly for the railway company in place, and specifically on the leisure market where passengers favor this transport mode: prices drop by more than $20 \%$. Secondly, this has the expected effect on market shares for all firms already on the market: they all loose traffic and this appears to be of particular magnitude for airlines on the leisure side, where we observe a fall of $20 \%$ to $50 \%$ depending on the share of the outside alternative. This new competitor affects more the different airlines than it affects DB, which looses less than $20 \%$ of its market share. The mechanisms here are the following ones. A new competitor starts to operate the link proposing very competitive fares, thanks to low marginal costs. The entrant has the same characteristics as DB's and offers tariffs closer (even lower) to Low Costs Airlines'. On the business market, where land transport is less appreciated by customers, we observe a moderate reaction of airlines for which the threat of a new train, even with low tariffs, is not of major impact. The more harmful consequences for firms of such a new market configuration concern traffic on the leisure segment. Before the entry of the Low Cost Train, people were more willing to travel by train than any other mode, speaking in terms of quality as shown in Table 3, but even so some passengers were attracted by the lower tariffs offered by airlines. Now, there is this new train, providing exactly the same service as DB's, then highly valued by customers, which proposes prices even smaller than the ones of Low Cost Airlines, not being able to reduce their prices of such an amount. The Low Cost train ends up capturing a significant proportion of the traffic. However the incumbent train operator 
is not totally driven out of the market and this can be explained by some external considerations for the consumers, like switching costs or imprecise information on the price differential which would lead travelers to choose the LCT. Capacity constraints on the link can also allow the two trains to operate the link. These effects, unobservable in our specification, could be identified if we had additional data.

A very significant effect to be underlined here concerns the portion of potential travelers preferring not to make the trip. This new alternative being less expensive, it forces firms already on the market to reduce their prices, and this has the global effect to induce traffic on both the existing market, and to a higher extent on the leisure segment. We can read on the table that changes in the outside option market share are negative and of substantial magnitude, between $20 \%$ and $50 \%$. From this follows an improvement in consumer surplus, which is of considerable magnitude on the leisure market.

\section{Effect of a new kerosene tax}

Our fourth simulation here consists in evaluating the effects of a change in the regulatory framework, for example here an environmental measure aiming at reducing exhaust emissions: the introduction of a kerosene tax of 65.45 cent/litre amounting to airlines cost increases (per pass-km) by $15 \%$. The results are presented in Table 6 . We can notice first that this increase in airlines costs induces an increase in their prices by nearly $10 \%$. This is also true for the other modes even if to a smaller extent. Expecting these higher prices the railway company anticipates a gain in traffic and increases its fares by a small amount to make more profit. This phenomenon is verified in the two markets, but is slightly more pronounced in the business market, where fares are higher because air carriers know that business passengers are less sensitive to variations in prices than leisure travelers. These changes in tariffs imply changes in demand and market shares, and as expected we find that airlines loose some relatively high proportions of traffic, between $7 \%$ and $18 \%$ for LCAs and between $20 \%$ and $35 \%$ for LH. These losses are partly transferred to other modes and even to the outside alternative category. These higher prices and loss in global traffic have a negative impact on consumer surplus if the induced environmental relief is not taken into account.

\section{Conclusion}


A first important conclusion to be drawn from this study concerns competition policy in the transport industry. To evaluate the effectiveness of competition on a particular market of transport services, we need to account for all potential travelers, all modes and all firms. This result should be useful for defining relevant markets. A second important conclusion is that, based on our framework and the lessons drawn from the counterfactual experiments we have discussed, a small number of competitors is enough to create a high degree of competition.

The model and methodology elaborated in this study constitute a useful and practical tool in the evaluation of market changes, both from firms and regulator viewpoints. This instrument allows us to predict market outcomes and welfare effects following some political or structural changes. Note that it can be applied in cases of oligopolistic competition when detailed data are not available.

If the method has proved to be performing well already, some more work is needed to capture specific or hidden effects, by relaxing some assumptions of our model. For instance, it would be interesting to incorporate flexible forms for the marginal costs, instead of considering them as constant, to introduce non linear prices as this is more appropriate to both air and train pricing, or to consider a larger network, with more than two nodes and a more complex structure of hubs and spokes. 
APPENDIX 1: Consumer choices

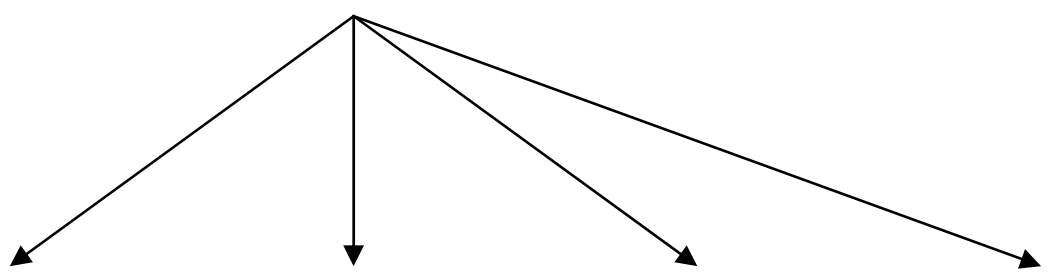

RAIL AIR

ROAD

OG
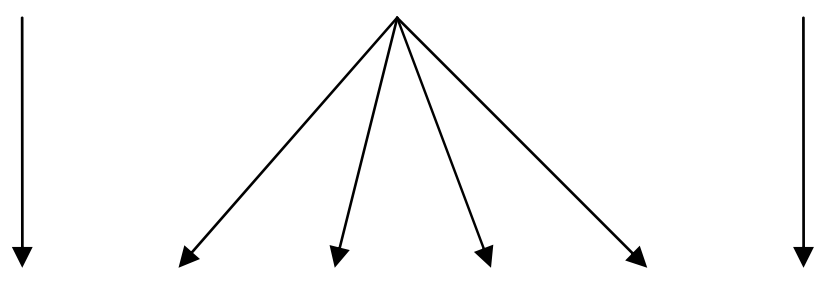

DB DBA HLX GW LH CAR 


\section{APPENDIX 2: Tables}

Table 1. Data on the link Cologne-Berlin.

\begin{tabular}{|c|c|c|c|c|c|c|c|c|c|c|c|}
\hline & & \multirow{2}{*}{$\begin{array}{c}\text { Traffic } \\
\text { Modal } \\
\text { Shares } \%\end{array}$} & \multicolumn{2}{|c|}{$\begin{array}{c}\text { Alternatives } \\
\text { Shares \% }\end{array}$} & \multicolumn{2}{|c|}{ Prices Euros } & \multirow{2}{*}{$\begin{array}{c}\text { Speed } \\
\mathrm{Km} / \mathrm{Min}\end{array}$} & \multirow{2}{*}{$\begin{array}{c}\text { Frequency } \\
\text { Trips/Day }\end{array}$} & \multirow{2}{*}{$\begin{array}{l}\text { Capacity } \\
\text { Seats/Trip }\end{array}$} & \multicolumn{2}{|c|}{ Marginal Costs* } \\
\hline & & & Business & Leisure & Business & Leisure & & & & Business & Leisure \\
\hline Rail & $D B$ & 31.1 & 15.7 & 51.4 & 90.0 & 60.0 & 138.5 & 16 & 736 & na & 13 \\
\hline \multirow{4}{*}{ Air } & $D B A$ & 14.8 & 19.2 & 9.1 & 169.0 & 51.2 & 404.6 & 8 & 136 & na & 26 \\
\hline & $H L X$ & 13.8 & 17.8 & 8.4 & 169.0 & 46.7 & 404.6 & 5 & 169 & na & 26 \\
\hline & $G \boldsymbol{W}$ & 8.2 & 10.6 & 5.0 & 169.0 & 46.1 & 404.6 & 4 & 111 & na & 26 \\
\hline & $L H$ & 14.3 & 18.5 & 8.7 & 240.0 & 53.4 & 404.6 & 9 & 123 & na & na \\
\hline Car & Car & 17.9 & 18.2 & 17.4 & 110.0 & 80.0 & 114.5 & Infinity & Infinity & na & na \\
\hline
\end{tabular}

* Estimates provided by DB.

Table 2. Equilibrium outcomes.

\begin{tabular}{|c|c|c|c|c|c|c|c|c|}
\hline \multirow{2}{*}{\multicolumn{3}{|c|}{ Share of the outside alternative }} & \multicolumn{3}{|c|}{ BUSINESS } & \multicolumn{3}{|c|}{ LEISURE } \\
\hline & & & $15 \%$ & $30 \%$ & $60 \%$ & $15 \%$ & $30 \%$ & $60 \%$ \\
\hline \multirow{7}{*}{$\begin{array}{c}\text { Market } \\
\text { Shares } \\
\%\end{array}$} & Rail & $D B$ & 13.3 & 10.1 & 6.3 & 43.7 & 36 & 20.6 \\
\hline & \multirow{4}{*}{ Air } & $D B A$ & 16.3 & 13.4 & 7.7 & 7.7 & 6.4 & 3.6 \\
\hline & & $H L X$ & 15.1 & 12.4 & 7.1 & 7.1 & 5.9 & 3.4 \\
\hline & & $G \boldsymbol{W}$ & 9 & 7.4 & 4.2 & 4.3 & 3.5 & 2 \\
\hline & & $L H$ & 15.7 & 12.9 & 7.4 & 7.4 & 6.1 & 3.5 \\
\hline & Car & Car & 15.5 & 12.7 & 7.3 & 14.8 & 12.2 & 7 \\
\hline & \multicolumn{2}{|c|}{ Outside alternative } & 15 & 30 & 60 & 15 & 30 & 60 \\
\hline \multicolumn{3}{|c|}{ Marginal Utility of Income } & 0.016 & 0.015 & 0.017 & 0.038 & 0.032 & 0.026 \\
\hline \multicolumn{3}{|c|}{$\begin{array}{c}\text { Coeff. of Within Group } \\
\text { Correlation }\end{array}$} & 0.21 & 0.22 & 0.36 & 0.25 & 0.26 & 0.28 \\
\hline \multirow{6}{*}{$\begin{array}{l}\text { Own Price } \\
\text { Elasticities }\end{array}$} & Rail & $D B$ & -1.25 & -1.21 & -1.3 & -1.29 & -1.25 & -1.23 \\
\hline & \multirow{4}{*}{ Air } & $D B A$ & -2.77 & -2.71 & -3.41 & -2.26 & -1.98 & -1.63 \\
\hline & & $H L X$ & -2.82 & -1.96 & -3.46 & -2.08 & -1.82 & -1.5 \\
\hline & & $G \boldsymbol{W}$ & -3.06 & -1.55 & -3.69 & -2.18 & -1.9 & -1.54 \\
\hline & & $\boldsymbol{L H}$ & -3.96 & -3.05 & -4.88 & -2.38 & -2.08 & -1.7 \\
\hline & Car & Car & -1.49 & -1.44 & -1.56 & -2.6 & -2.28 & -1.92 \\
\hline \multicolumn{3}{|c|}{ Consumer Surplus } & 118 & 80 & 33 & 50 & 37 & 20 \\
\hline
\end{tabular}


Table 3. Calibration of the quality index and its components.

\begin{tabular}{|c|c|c|c|c|c|c|c|c|}
\hline \multirow{2}{*}{\multicolumn{3}{|c|}{ Share of the outside alternative }} & \multicolumn{3}{|c|}{ BUSINESS } & \multicolumn{3}{|c|}{ LEISURE } \\
\hline & & & $15 \%$ & $30 \%$ & $60 \%$ & $15 \%$ & $30 \%$ & $60 \%$ \\
\hline \multirow{6}{*}{$\begin{array}{c}\text { Quality, } \\
\text { Mode Ranking }\end{array}$} & Rail & $D B$ & 1.33 & 0.35 & -0.87 & 3.36 & 2.13 & 0.47 \\
\hline & \multirow{4}{*}{ Air } & $D B A$ & 3.05 & 2.01 & 0.98 & 1.6 & 0.44 & -1.14 \\
\hline & & $H L X$ & 2.99 & 1.96 & 0.93 & 1.37 & 0.23 & -1.32 \\
\hline & & $G \boldsymbol{W}$ & 2.58 & 1.55 & 0.6 & 0.96 & -0.16 & -1.71 \\
\hline & & $L H$ & 4.16 & 3.06 & 2.04 & 1.65 & 0.47 & -1.12 \\
\hline & Car & Car & 1.8 & 0.8 & -0.42 & 3.04 & 1.7 & -0.09 \\
\hline \multirow{6}{*}{$\begin{array}{c}\text { Quality } \\
\text { characteristics }\end{array}$} & \multicolumn{2}{|c|}{ DB Dummy } & -2.78 & -2.35 & -1.85 & -1.85 & -1.5 & -1.14 \\
\hline & \multicolumn{2}{|c|}{ LCA Dummy } & -14 & -10.28 & -5.72 & -18.4 & -15.01 & -10.9 \\
\hline & \multicolumn{2}{|c|}{ LH Dummy } & -14.1 & -10.21 & -5.61 & -19.43 & -16.0 & -12.1 \\
\hline & \multicolumn{2}{|c|}{ Speed } & 0.94 & 0.46 & -0.25 & 1.58 & 0.97 & -0.002 \\
\hline & \multicolumn{2}{|c|}{1 / Frequency } & -1.57 & -1.38 & -1.22 & -3.94 & -3.67 & -3.29 \\
\hline & \multicolumn{2}{|c|}{1 / Capacity } & 1499.9 & 1313.2 & 1168 & 1320.5 & 1275.1 & 1392.9 \\
\hline
\end{tabular}

Table 4: Simulation of the entry of Low Cost Airlines in 2002.

\begin{tabular}{|c|c|c|c|c|c|c|c|c|}
\hline \multirow{3}{*}{\multicolumn{3}{|c|}{\begin{tabular}{|l}
$\begin{array}{l}\text { Share of the outside } \\
\text { alternative }\end{array}$ \\
Changes: values, \% \\
\end{tabular}}} & \multicolumn{6}{|c|}{ LEISURE } \\
\hline & & & \multicolumn{2}{|c|}{$20 \%$} & \multicolumn{2}{|c|}{$35 \%$} & \multicolumn{2}{|c|}{$65 \%$} \\
\hline & & & Value & $\begin{array}{c}\text { Change } \\
\%\end{array}$ & Value & $\begin{array}{c}\text { Change } \\
\%\end{array}$ & Value & $\begin{array}{c}\text { Change } \\
\%\end{array}$ \\
\hline \multirow{6}{*}{ Prices } & Rail & $D B$ & 57.5 & $-4.3 \%$ & 58.5 & $-2.5 \%$ & 59.6 & $-0.61 \%$ \\
\hline & \multirow{4}{*}{ Air } & $D B A$ & 52.7 & $-12.2 \%$ & 51.7 & $-13.7 \%$ & 51.9 & $-13.4 \%$ \\
\hline & & $H L X$ & 46.9 & & 45.6 & & 46.1 & \\
\hline & & $G W$ & 47.7 & & 46.2 & & 46.8 & \\
\hline & & $L H$ & 69.3 & $-0.92 \%$ & 66.2 & $-5.44 \%$ & 67.5 & $-3.5 \%$ \\
\hline & Car & Car & 79.3 & $-0.92 \%$ & 79.5 & $-0.57 \%$ & 79.8 & $-0.14 \%$ \\
\hline \multirow{7}{*}{$\begin{array}{c}\text { Market } \\
\text { Shares } \\
\%\end{array}$} & Rail & $D B$ & 41.6 & $-8.8 \%$ & 35 & $-5.4 \%$ & 19 & $-4.41 \%$ \\
\hline & \multirow{4}{*}{ Air } & $D B A$ & 9.2 & $14.45 \%$ & 6.5 & $-0.54 \%$ & 4 & $13.3 \%$ \\
\hline & & $H L X$ & 6.1 & & 4.7 & & 2.8 & \\
\hline & & $\boldsymbol{G W}$ & 5.2 & & 3.9 & & 2.4 & \\
\hline & & $L H$ & 8.5 & $-18.5 \%$ & 6.5 & $-23.1 \%$ & 3.8 & $-16.4 \%$ \\
\hline & Car & Car & 13.3 & $-16.6 \%$ & 11.9 & $-8.6 \%$ & 6.6 & $-5.3 \%$ \\
\hline & \multicolumn{2}{|c|}{ Outside alternative } & 16 & $-19.6 \%$ & 31.5 & $-9.9 \%$ & 61.3 & $-5.7 \%$ \\
\hline \multicolumn{3}{|c|}{ Consumer Surplus } & 36.8 & & 35.9 & & 13.2 & \\
\hline
\end{tabular}


Table 5. Simulation of the entry of a Low Cost Train.

\begin{tabular}{|c|c|c|c|c|c|c|c|c|c|c|c|c|c|c|}
\hline \multirow{3}{*}{\multicolumn{3}{|c|}{$\begin{array}{l}\text { Share of the outside } \\
\text { alternative } \\
\text { Changes: values, \% }\end{array}$}} & \multicolumn{6}{|c|}{ BUSINESS } & \multicolumn{6}{|c|}{ LEISURE } \\
\hline & & & \multicolumn{2}{|c|}{$15 \%$} & \multicolumn{2}{|c|}{$30 \%$} & \multicolumn{2}{|c|}{$60 \%$} & \multicolumn{2}{|c|}{$15 \%$} & \multicolumn{2}{|c|}{$30 \%$} & \multicolumn{2}{|c|}{$60 \%$} \\
\hline & & & Value & $\begin{array}{c}\text { Change } \\
\%\end{array}$ & Value & $\begin{array}{c}\text { Change } \\
\%\end{array}$ & Value & $\begin{array}{c}\text { Change } \\
\%\end{array}$ & Value & $\begin{array}{c}\text { Change } \\
\%\end{array}$ & Value & $\begin{array}{c}\text { Change } \\
\%\end{array}$ & Value & $\begin{array}{c}\text { Change } \\
\%\end{array}$ \\
\hline \multirow{7}{*}{ Prices } & Rail & $D B$ & 79.00 & $-12.2 \%$ & 78.6 & $-12.7 \%$ & 72.7 & $-19.2 \%$ & 44.2 & $-26.4 \%$ & 45.7 & $-23.8 \%$ & 48.9 & $-18.5 \%$ \\
\hline & & New Train & 72.20 & & 72.6 & & 65.2 & & 40.9 & & 42.5 & & 45.2 & \\
\hline & \multirow{4}{*}{ Air } & $D B A$ & 167.80 & $-0.7 \%$ & 168.2 & $-0.5 \%$ & 168.8 & $-0.11 \%$ & 50.5 & $-1.4 \%$ & 50.7 & $-1.0 \%$ & 51 & $-0.4 \%$ \\
\hline & & $H L X$ & 167.90 & $-0.7 \%$ & 168.3 & $-0.4 \%$ & 168.8 & $-0.10 \%$ & 46 & $-1.4 \%$ & 46.2 & $-1.0 \%$ & 46.5 & $-0.4 \%$ \\
\hline & & $G \boldsymbol{W}$ & 168.40 & $-0.4 \%$ & 168.6 & $-0.2 \%$ & 168.9 & $-0.06 \%$ & 45.8 & $-0.8 \%$ & 45.9 & $-0.6 \%$ & 46 & $-0.2 \%$ \\
\hline & & $\mathrm{LH}$ & 238.80 & $-0.5 \%$ & 239.2 & $-0.3 \%$ & 240 & $-0.07 \%$ & 52.7 & $-1.3 \%$ & 52.9 & $-0.9 \%$ & 53.2 & $-0.3 \%$ \\
\hline & Car & Car & 108.40 & $-1.5 \%$ & 108.9 & $-1.0 \%$ & 109.6 & $-0.32 \%$ & 77.7 & $-2.8 \%$ & 78.3 & $-2.1 \%$ & 79.4 & $-0.8 \%$ \\
\hline \multirow{8}{*}{$\begin{array}{c}\text { Market } \\
\text { Shares } \\
\quad \%\end{array}$} & \multirow{2}{*}{ Rail } & $D B$ & 11.6 & $-13.1 \%$ & 9.8 & $-11.1 \%$ & 5.7 & $-8 \%$ & 32.6 & $-25.4 \%$ & 28.2 & $-21.6 \%$ & 17.5 & $-15.0 \%$ \\
\hline & & New Train & 13.3 & & 10.9 & & 6.9 & & 38.5 & & 32.5 & & 19.9 & \\
\hline & \multirow{4}{*}{ Air } & $D B A$ & 14.2 & $-13.0 \%$ & 12 & $-10.5 \%$ & 7.2 & $-6.60 \%$ & 3.9 & $-49.0 \%$ & 3.9 & $-38.6 \%$ & 2.9 & $-20.9 \%$ \\
\hline & & $H L X$ & 13.1 & $-13.2 \%$ & 11.1 & $-10.6 \%$ & 6.6 & $-6.60 \%$ & 3.6 & $-49.2 \%$ & 3.6 & $-38.7 \%$ & 2.7 & $-21.0 \%$ \\
\hline & & $G \boldsymbol{W}$ & 7.7 & $-14.0 \%$ & 6.6 & $-11.2 \%$ & 4 & $-6.80 \%$ & 2.1 & $-50.0 \%$ & 2.1 & $-39.2 \%$ & 1.6 & $-21.1 \%$ \\
\hline & & $\boldsymbol{L H}$ & 13.7 & $-13.1 \%$ & 11.6 & $-10.6 \%$ & 6.9 & $-6.60 \%$ & 3.8 & $-49.1 \%$ & 3.7 & $-38.6 \%$ & 2.8 & $-20.9 \%$ \\
\hline & Car & Car & 13.5 & $-12.4 \%$ & 11.4 & $-10.1 \%$ & 6.8 & $-6.40 \%$ & 8 & $-46.0 \%$ & 7.8 & $-36.2 \%$ & 5.6 & $-20.0 \%$ \\
\hline & \multicolumn{2}{|c|}{ Outside alternative } & 12.8 & $-14.7 \%$ & 26 & $-11.7 \%$ & 55.8 & $-7 \%$ & 7.4 & $-50.5 \%$ & 18.1 & $-39.6 \%$ & 47.2 & $-21.3 \%$ \\
\hline \multicolumn{3}{|c|}{ Consumer Surplus } & 128.00 & $8 \%$ & 88 & $10 \%$ & 38 & $15 \%$ & 68 & $36 \%$ & 53 & $43 \%$ & 29 & $45 \%$ \\
\hline
\end{tabular}


Table 6. Simulation of the effect of a kerosene tax.

\begin{tabular}{|c|c|c|c|c|c|c|c|c|c|c|c|c|c|c|}
\hline \multirow{3}{*}{\multicolumn{3}{|c|}{$\begin{array}{l}\text { Share of the outside } \\
\text { alternative } \\
\text { Changes: values, \% }\end{array}$}} & \multicolumn{6}{|c|}{ BUSINESS } & \multicolumn{6}{|c|}{ LEISURE } \\
\hline & & & \multicolumn{2}{|c|}{$15 \%$} & \multicolumn{2}{|c|}{$30 \%$} & \multicolumn{2}{|c|}{$60 \%$} & \multicolumn{2}{|c|}{$15 \%$} & \multicolumn{2}{|c|}{$30 \%$} & \multicolumn{2}{|c|}{$60 \%$} \\
\hline & & & Value & $\begin{array}{c}\text { Change } \\
\%\end{array}$ & Value & $\begin{array}{c}\text { Change } \\
\%\end{array}$ & Value & $\begin{array}{c}\text { Change } \\
\%\end{array}$ & Value & $\begin{array}{c}\text { Change } \\
\%\end{array}$ & Value & $\begin{array}{c}\text { Change } \\
\%\end{array}$ & Value & $\begin{array}{c}\text { Change } \\
\%\end{array}$ \\
\hline \multirow{6}{*}{ Prices } & Rail & $D B$ & 91.7 & $1.84 \%$ & 91 & $1.2 \%$ & 90.3 & $0.37 \%$ & 60.8 & $1.38 \%$ & 60.4 & $0.72 \%$ & 60.1 & $0.14 \%$ \\
\hline & \multirow{4}{*}{ Air } & $D B A$ & 184.7 & $9.30 \%$ & 184.5 & $9.2 \%$ & 186.8 & $10.50 \%$ & 55.3 & $8 \%$ & 54.9 & $7.20 \%$ & 54.1 & $5.64 \%$ \\
\hline & & HLX & 184.9 & $9.40 \%$ & 184.6 & $9.3 \%$ & 186.9 & $10.60 \%$ & 50.2 & $7.70 \%$ & 49.8 & $6.70 \%$ & 49 & $5.00 \%$ \\
\hline & & $G \boldsymbol{G}$ & 185.7 & $9.90 \%$ & 185.4 & $9.7 \%$ & 187.4 & $10.90 \%$ & 49.8 & $8.00 \%$ & 49.4 & $7.00 \%$ & 48.6 & $5.30 \%$ \\
\hline & & $\mathrm{LH}$ & 264.4 & $10.20 \%$ & 264.5 & $10.2 \%$ & 266.9 & $11.20 \%$ & 57.8 & $8.30 \%$ & 57.3 & $7.50 \%$ & 56.5 & $6.00 \%$ \\
\hline & Car & Car & 112.0 & $1.80 \%$ & 111.2 & $1.1 \%$ & 110.4 & $0.35 \%$ & 80.2 & $0.30 \%$ & 80.1 & $0.16 \%$ & 80.03 & $0.03 \%$ \\
\hline \multirow{7}{*}{$\begin{array}{l}\text { Market } \\
\text { Shares\% }\end{array}$} & Rail & $D B$ & 15.3 & $14.6 \%$ & 12.2 & $11.1 \%$ & 6.7 & $7.10 \%$ & 44.6 & $2.25 \%$ & 36.5 & $1.58 \%$ & 20.7 & $0.68 \%$ \\
\hline & \multirow{4}{*}{ Air } & $D B A$ & 15.1 & $-7.5 \%$ & 12.1 & $-9.6 \%$ & 6.4 & $-16 \%$ & 6.9 & $-10.00 \%$ & 5.8 & $-8.71 \%$ & 3.4 & $-6.50 \%$ \\
\hline & & $H L X$ & 13.9 & $-7.8 \%$ & 11.2 & $-9.9 \%$ & 5.9 & $-16.50 \%$ & 6.6 & $-7.50 \%$ & 5.5 & $-6.47 \%$ & 3.2 & $-4.60 \%$ \\
\hline & & $G \boldsymbol{W}$ & 8.2 & $-9.4 \%$ & 6.6 & $-11.3 \%$ & 3.5 & $-17.40 \%$ & 3.9 & $-8.02 \%$ & 3.3 & $-6.97 \%$ & 1.9 & $-4.90 \%$ \\
\hline & & $L H$ & 12.2 & $-22.5 \%$ & 9.8 & $-24.0 \%$ & 5 & $-33 \%$ & 6.6 & $-11.40 \%$ & 5.5 & $-10 \%$ & 3.2 & $-7.50 \%$ \\
\hline & Car & Car & 17.7 & $14.1 \%$ & 14.1 & $10.8 \%$ & 7.8 & $7.05 \%$ & 15.4 & $4.60 \%$ & 12.5 & $2.60 \%$ & 7 & $0.80 \%$ \\
\hline & \multicolumn{2}{|c|}{\begin{tabular}{|l|} 
Outside \\
alternative
\end{tabular}} & 17.6 & $17.7 \%$ & 33.9 & $12.9 \%$ & 64.6 & $8 \%$ & 15.8 & $6 \%$ & 31 & $3 \%$ & 60.5 & $1 \%$ \\
\hline \multicolumn{3}{|c|}{ Consumer Surplus } & 108.00 & $-8 \%$ & 72 & $-10 \%$ & 29 & $-12 \%$ & 48 & $-4 \%$ & 36 & $-3 \%$ & 19.5 & $-3 \%$ \\
\hline
\end{tabular}




\section{APPENDIX 3: Model Calibration.}

\section{Step 1}

The choice structure studied here comprises the six existing alternatives to go from Cologne to Berlin. There are six own-price elasticity equations and we solve the system for $h$ and $\sigma$. Recall that we do not have values for the elasticities.

To deal with these identification problems, we start by re-parameterizing the model in the following way:

$$
\begin{aligned}
& \eta_{j}=h p_{j}\left(p_{j}-\frac{1}{1-\sigma}+\frac{\sigma}{1-\sigma} s_{j / g}\right) \\
& \eta_{j}=a\left(p_{j} s_{j}-p_{j}\right)+b\left(p_{j} s_{j / g}-p_{j}\right)
\end{aligned}
$$

with $a=h$ and $\sigma=\frac{b}{a+b}$.

Next, we generate repeatedly ( $K=1000$ times) a random vector of elasticities, normally distributed. The mean of the distribution was chosen to be close to the values we find in the literature (Oum, Waters and Young, 1990). We find the parameters $a$ and $b$ which minimize the average difference between the random vectors of elasticities and their associated expression provided in Equation (A.1), i.e., which are solutions of the following program:

$$
\underset{a, b}{\operatorname{Min}}\left(\sum_{k=1}^{K}\left(\sum_{j=1}^{6}\left(\eta_{j}^{k}-a\left(p_{j} s_{j}-p_{j}\right)-b\left(p_{j} s_{j / g}-p_{j}\right)\right)^{2}\right)\right) .
$$

We are able to form $95 \%$ confidence intervals for these parameters. We obtain:

$$
\begin{aligned}
& 0.030 \leq a \leq 0.034 \\
& 0.010 \leq b \leq 0.015
\end{aligned}
$$

Then we solve for values for $h$ and $\sigma$.

\section{Step 2}

We compute the marginal costs according to the system defined by Equations (A.4):

$$
c_{j}=p_{j}-\frac{1-\sigma}{h\left(1-\sigma s_{f / g}-(1-\sigma) s_{f}\right)}
$$


This procedure is repeated until we find a vector for marginal cost as close as possible to the values of marginal costs that we already know. We keep the latest values for $h, \sigma$, and the values of elasticities and marginal costs.

\section{Step 3}

It is straightforward to solve for the weight of components of the quality index using the system of Equations (A.5):

$$
\psi_{j}=-h p_{j}+\sigma \ln \left(s_{j / g}\right)-\left(\ln \left(s_{j}\right)-\ln \left(s_{0}\right)\right)
$$

\section{Step 4}

We can express this aggregate measure of quality as the weighted sum of the characteristics of alternatives. We find the different parameters associated with them by solving the following system of six equations and six unknowns:

$$
\psi_{j}=\alpha_{1} D 1_{j}+\alpha_{2} D 2_{j}+\alpha_{3} D 3_{j}+\beta_{1} \text { speed }_{j}+\beta_{2}\left(\frac{1}{\text { freq }_{j}}\right)+\beta_{3}\left(\frac{1}{\text { cap }_{j}}\right)
$$

with variable $D 1$ taking value 1 if $j=D B$, variable $D 2$ taking value 1 if $j=D B A, H L X$, or $G W$ and variable $D 3$ taking value 1 if $j=L H$. The argument for this is the existing differences between LCAs and the LH, even if classified in the same group. The measures of frequency and capacity are inverted to take into account the specificity of the alternative "car", for which we can consider infinite frequencies and capacities. 


\section{REFERENCES}

Antes, J., G. Friebel, M. Niffka and D. Rompf (2004), "Entry of Low-Cost Airlines in Germany. Some Lessons for the Economics of Railroads and Inter-Modal Competition", mimeo, Deutsche Bahn and University of Toulouse.

Berry, S. T. (1994), "Estimating Discrete-Choice Models of Product Differentiation", The RAND Journal of Economics, vol. 25, Issue 2, pp. 242-262.

European Commission (2003), European Union Energy and Transport in Figures, Directorate General for Energy and Transport, in cooperation with Eurostat, Brussels.

Glass, A. (2003), “An Assessment of the Desirability of On-Track Competition: The IpswichLondon route", Institute of Transport Studies, University of Leeds.

Holvad, T., B. Huang and J. Preston, "Review of Introduction of Competition in railways in Europe", Transport Studies Unit, University of Oxford.

IDEI (2003), "The Economics of Passenger Rail Transport: A Survey". http://www.idei.fr/doc/wp/2003/rapport_db_1.pdf.

IDEI (2003), "Entry in the Passenger Rail Industry: A Theoretical Investigation". http://www.idei.fr/doc/wp/2003/rapport2_db_2.pdf.

Ivaldi, M. and F. Verboven (2004), "Quantifying the Effects from Horizontal Mergers in European Competition Policy", International Journal of Industrial Organization, forthcoming.

Johnson, D. and G. Whelan (2003), "Modelling the Impact of Alternative Fare Structures", Institute of Transport Studies, University of Leeds.

McFadden, D. (1974), “The Measurement of Urban Travel Demand", Journal of Public Economics, vol. 3, pp. 303-325.

Nash, C. and C. Rivera-Trujillo (2004), "Rail Regulatory Reform in Europe, Principles and Practice", Institute of Transport Studies, University of Leeds.

Oum, T. H., W.G. Waters and Jon Say Yong (1990), “A Survey of Recent Estimates of Price Elasticities of Demand for Transport", Infrastructure and Urban Development Department, the Worldbank.

Preston, J., M. Wardman and G. Whelan (1999), “An Analysis of the Potential for On-Track Competition in the British Passenger Rail Industry", Journal of Transport Economics and Policy, vol. 33, part 1, pp. 77-94. 